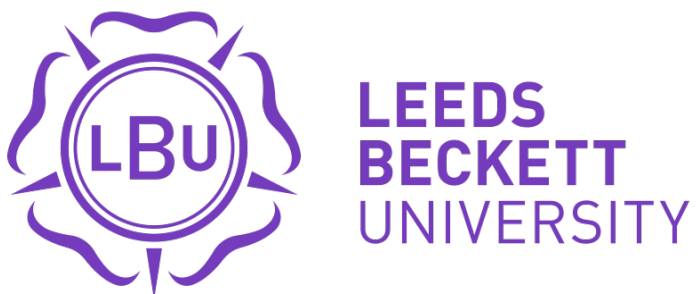

\section{Citation:}

Morgan, JA and Patomäki, H (2017) Contrast explanation in economics its context, meaning, and potential. Cambridge Journal of Economics, 41 (5). pp. 1391-1418. ISSN 0309-166X DOI: https://doi.org/10.1093/cje/bex033

Link to Leeds Beckett Repository record:

https://eprints.leedsbeckett.ac.uk/id/eprint/3800/

Document Version:

Article (Accepted Version)

The aim of the Leeds Beckett Repository is to provide open access to our research, as required by funder policies and permitted by publishers and copyright law.

The Leeds Beckett repository holds a wide range of publications, each of which has been checked for copyright and the relevant embargo period has been applied by the Research Services team.

We operate on a standard take-down policy. If you are the author or publisher of an output and you would like it removed from the repository, please contact us and we will investigate on a case-by-case basis.

Each thesis in the repository has been cleared where necessary by the author for third party copyright. If you would like a thesis to be removed from the repository or believe there is an issue with copyright, please contact us on openaccess@leedsbeckett.ac.uk and we will investigate on a case-by-case basis. 


\title{
Contrast explanation in economics: its context, meaning, and potential ${ }^{\circ}$
}

\author{
Jamie Morgan \& Heikki Patomäki
}

In this article we place Tony Lawson's account of contrast explanation in context. Lawson's development of it is given meaning both by the roots of the approach in his work on social ontology and the state of economics that provides the grounds for the critique contained in that social ontology. This is important because such an approach to explanation is not new. Most notably van Fraassen and Garfinkel have developed it in particular ways and for particular purposes within the philosophy of science and social theory. Setting out the different ways in which the contrastive approach has been developed is useful for identifying what is different about Lawson's approach, its potential and limits. Lawson's proposal is more modest and focusses on causal investigation in a manner that flows from his approach to social ontology. Contrast explanation provides a substitute for controlled experiments and facilitates identifying social mechanisms. It also enables exploration of the manifold presuppositions of our explanatory questions. We argue that this is a useful and important contribution to overcoming some of the many problems economics faces.

Key words: contrast explanation, social ontology, Lawson, Garfinkel, van Fraassen

JEL classifications: A10, A11, B41, B50

\section{Introduction: contrast explanation as one approach to a generalised problem}

In Economics \& Reality (1997, pp. 199-226) and Reorienting Economics Lawson develops his account of contrast explanation (2003, pp. 86-109; 2009, pp. 407-408). According to it the starting point for an explanatory project is an awareness of a tension. For example this may be an observation of a significant unexpected or unusual outcome in some particular context or 'contrast space', of sufficient interest (relative to current understandings) to provoke (and make worthwhile) a comparative 'why' question: 'why $x$ rather than $y$ '. The latter expresses the contrast, between an observation and something that was expected. The general form is simple and highly flexible. Lawson specifically introduces contrast explanation as a dialectically reasoned investigative approach that is compatible with, and can be developed in terms of, his longstanding work on social ontology (2009, pp. 405-406).

Social ontology concerns the study of the nature of social reality. Lawson's work on social ontology involves a wide-ranging critique of the current state of economics. Contrast explanation is an approach set out as one potential contribution to addressing the general problems of the claimed parlous state of economics. As such, Lawson's use of contrast explanation is given meaning both by its roots in his work on social ontology and the state of economics that provides the grounds for the critique contained in that social ontology. This point is important. Contrast explanation is not new. It is an

\footnotetext{
- We would like to thank Tuomas Forsberg, Uskali Mäki and the PhD candidate participants at the 'Varieties of explanation in economics, politics and global political economy' workshop, University of Helsinki, May 3-4, 2016, for useful discussions that informed this paper.
} 
approach articulated and developed in different ways within philosophy and across the social sciences. Not all of these ways coincide with Lawson's concerns. Concomitantly, his use of contrast explanation and its relevance in economics can easily be misunderstood if isolated from its roots in social ontology. One issue is that the potentials for contrast explanation are partly expressed through the possibility of experimental conditions (which are a 'special case' of the grounds for contrast explanation). This can easily be misunderstood since mainstream economics stresses the possibility of progress through quasi-experimental research design.

In the sections that follow we first set out briefly the general context of economics within which social ontology has emerged. Our exposition serves two purposes. First it gives a sense of the conditions that have motivated a concern with social ontology and that continue to make it a relevant domain of argument within and for economics. The problems of economics are longstanding and widespread. Though there are differences in regard of the emphasis of critique there is also an underlying continuity and commonality to critique. It has consistently questioned the realism and relevance of the mainstream. What is considered "realistic" depends on our philosophical and socialtheoretical conception of reality.

Second, we set out the key characteristics of contrast explanation as developed within philosophy and within the social sciences. This highlights two further points. First, social ontology shapes the scope of contrast explanation, and second, social ontology maintains the distinction between philosophical ontology, social-scientific ontology (social theory), and concrete claims about geo-historical reality. This is important because otherwise philosophy can appear to claim too much in terms of its role in and for social science and economics. We argue that Lawson's approach to contrast explanation is positioned to avoid this problem. Contrast explanation, as noted, is not intended to, nor can it, settle all problems of how and what one researches. Rather, contrast explanation, in its various guises, stresses the conceptual, pragmatic, ethical and political context of explanation.

\section{The significance of social ontology as a response to the state of economics}

Contemporary economics has been subject to widespread critique (e.g. Boyer, 2013; Dow, 2012; Fine, 2013; Fullbrook, 2009; Lawson, 2015; Harcourt, 2010; Hodgson, 2009; Sawyer, 2011). One widely acknowledged aspect of this critique is that the history of economic thought and the methodology and philosophy of economics are no longer typical constituents of an economics education (e.g. Morgan, 2015b). Over time this has meant that these research fields are no longer constitutive for the majority of academic economists. As such, the latter cannot easily draw on the noted fields as sources of insight and expertise in the construction of theory, in applied work, and in the broader critical engagement between theories and applications.

Although the mainstream has tended to become less concerned with realism it has not eschewed claims of applied relevance, or simply shed a language of realism. Rather the way in which these are expressed has been shaped by the fundamentals of the mainstream. ${ }^{1}$ Theory is produced with caveats ('this form may be applicable to reality'), theory is held to different standards (is the realism of axioms etc. really an issue?), models are defended, developed and critiqued according to a language of progress, where the model is stated as 'more realistic', but where the model tries, arguably, to

\footnotetext{
${ }^{1}$ Dani Rodrik (2015) provides the most articulate contemporary illustration of the points we set out here. Syll (2016) provides an excellent critique.
} 
render a 'more realistic' version of an unrealism. Discussion of methods recognizes problems, but again expresses those problems within a discourse of 'progress', typically subsuming problems within the ordinary course of science, as a continual struggle in pursuit of rigour. So, widespread problems such as an inability to converge on a comprehensive set of variables, an inability to reproduce coefficients, an inability to generate insights that hold in empirically meaningful ways beyond an experiment or laboratory situation, and continual problems of forecasting and prediction, become hallmarks of the activity of science rather than a reason to acknowledge that the entire enterprise may fail to be scientific. This being so, if the mainstream had a maxim, it would be: recognizing failure but phrasing it through progress is no failure at all...

A language of progress resists recognizing that failure may be endemic, and resists recognizing that endemic failure may have underlying features. This has remained the case through the period of formalism in the later twentieth century and into the contemporary era, sometimes referred to as the 'empirical turn' (and more latterly the 'credibility revolution') in mainstream economics. Throughout, mainstream economics has changed, innovated and diversified, but it has not transformed. In some ways its ability to resist fundamental change have actually been augmented. For example, as the work of Fred Lee and various collaborators establishes, the Research Assessment Exercise (RAE) and Research Excellence Framework (REF) in the UK have resulted in the gradual elimination of non-mainstream economists from the majority of economics departments because they are less likely to publish in core mainstream journals (e.g. Lee et al, 2013; however, see also Colander, 2009; Colander, 2010). The elimination reduces the scope for mainstream economists and also for students to be exposed to a wider range of positions and ideas within economics.

The insularity fostered by the selection processes of the mainstream, combined with the status effects of the pervasiveness of economics (which inter alia give the impression of non-insularity through the conflation of pervasive with invasive) have, arguably, positioned the mainstream as a knowledge reproducing form able to deflect accusations of failure. This has been repeatedly demonstrated: mainstream economics remains basically unaffected by the widespread critique that followed the global financial crisis, and it remains essentially unresponsive (and in some cases responsively hostile) to the student organizations that have subsequently emerged because of that critique. $^{2}$

The point we want to emphasise here is that critique has consistently questioned the realisticness and relevance of the mainstream. It has done so with reference to its theory, its models and its empirical claims based on methods used. It has done so with reference to the mainstream's ability to reproduce itself in ways that are centrifugal for alternatives and centripetal for core commitments that perpetuate problems of realism, even as the mainstream changes. The mainstream is highly influential in the real world, but based on a discourse that acknowledges yet deflects problems of its own realisticness.

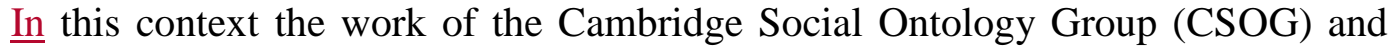
Lawson has been of huge value within economics (Morgan, 2016a; Lee and Cronin, 2016; Jo et al, 2017). Clearly, critique of the mainstream in terms of particular theory, models and methods has always been methodologically and philosophically informed. The work of Marx, Keynes, Veblen, Sraffa, Hayek, and many others since, involve basic claims that their targets were inadequate as ways to theorise and explore real

\footnotetext{
${ }^{2}$ This is despite significant investment from new organizations such as the Institute for New Economic Thinking (INET). See Association for Heterodox Economics (2014).
} 
economies. ${ }^{3}$ The work of CSOG and of Lawson has provided a way to capture the commonality of critique and so potentially commensurate the concerns of these multiple points of view.

CSOG and Lawson have provided an important body of work beginning from methodology and philosophy of economics (see Downward, 2003; Fleetwood, 1999; Fullbrook, 2009; Lawson et al, 2007; Lewis, 2004; Pratten, 2015). That work has made use of history of economic thought, and also 'immanent critique' of different aspects of economics, in order to develop economics as also social theory (Lawson, 1997; Lawson 2003). ${ }^{4}$ As such, it has demonstrated the general relevance of methodology, philosophy, history of economic thought and social theory for the economist. At the same time, in so far as it has attempted to capture the commonality of concerns with being realistic it has also shifted the terms of debate of methodology and philosophy of economics. To a significant degree, prior to the work of CSOG and Lawson, methodology and philosophy of economics, had become sub-disciplines, facilitating the concerns of the mainstream (though ironically were often considered mainly irrelevant). Those involved explored economics with reference to the quasi-natural science status of economics and drew on dominant theories in analytical philosophy of science. As such, the terms of analysis were always about standards and foci that neither the mainstream nor more pluralistic or heterodox economics could achieve.

Work on social ontology has gradually shifted the emphasis from paradigms, research programmes, positivism, empiricism, verification etc. to the more fundamental question: what would economic reality have to be like in order for the approaches pursued to be appropriate? This deceptively simple question has opened up a different way to explore the arising issues in economics. The work has resonated with the concerns already articulated in the methodological and philosophical aspects of existing critique, whilst also providing a new framework for assessing the consistency of both the mainstream and heterodox alternatives (compare chapters 3 and 4, Lawson, 2015a). It has thereby provided a means for heterodox economists to make sense of the multiple aspects of critique of the mainstream, but also to make sense of potential commonalities within heterodox economics as alternatives. Moreover, it has done so in ways able both to express the potentials of existing heterodox approaches and also to support new nonmainstream approaches (beyond existing schools). ${ }^{5}$

One might, therefore, argue that CSOG and the work of Lawson is, though rooted in methodology and philosophy of economics, more appropriately understood as transcending the boundaries of methodology and philosophy, at least in terms of the way the two had become sub-disciplinary. The work has provided a way to make explicit what has always been implicit: that heterodoxy and non-mainstream economics

\footnotetext{
${ }^{3}$ Referring to these well-known names is not intended to detract from or silence the work of subsequent and more contemporary contributors (a problem Thomas Palley notes in his Gattopardo economics essay) 4 Immanent critique explores the presuppositions, substantive premises, and truth-claims where multiplicity converges within some field of inquiry. It considers the terms under which tensions, contradictions and problems arise, and addresses itself to those. As such, immanent critique is variety of applied philosophy. It is not an alien discourse imposed on a field because its very form is rooted in the problematics of the field in which it is immersed. However, the intention is to seek ways to transcend common problematics, so tensions do arise.

${ }^{5}$ This has also had an organizational basis. Lawson has been editor of the Routledge Economics as Social Theory book series for many years. The series has published many important and diverse works, including for example Nancy Folbre's Who Pays for the Kids (1994). Lawson's work has for example, also been influential across subjects as diverse as ecological economics (see Spash, 2013) and business studies (see Jackson et al, 2016).
} 
are often the realistic alternatives to scientism. ${ }^{6}$ Within this function, CSOG and the work of Lawson have contributed to a constructive pluralism, rather than a narrow technical pluralism (see Dow, 2004; Dobusch and Kapeller 2012). ${ }^{7}$

However, the contributions and significance of the work of CSOG and of Lawson are not limited to critique but involves reconstruction, especially in terms of contrast explanation. We argue that Lawson's approach to contrast explanation has a history and context in the development of economics. The particular issues and problems of economics have in turn created the concern with ontology, and with realism in particular. Lawson makes this quite explicit in the main paper he has written on contrast explanation (subsequent to its introduction in Economics \& Reality and Reorienting Economics). In 2009 Cambridge Journal of Economics ran a special section, 'The intellectual legacy of Brian Reddaway'. Lawson's contribution is an extended illustration of contrast explanation using George Akerlof's well-known 'The market for 'lemons"' (2009). In the introduction Lawson states:

The modern discipline of economics, or at least its dominant mainstream branch, has, to a fairly significant extent, lost touch with the real world... the reason for this state of affairs is the more or less compulsory focus on formalistic models: we [Reddaway and I] shared the assessment that, by their nature, the sorts of models that economists use preclude the uncovering of very much real insight into social reality, given its nature. Furthermore, we were both convinced that realistic assessments of economic developments remained entirely feasible... my concern has been to elaborate this nature, and to investigate whether any insights obtained by doing so can provide some kind of aid to socio-explanatory enquiry. In short, my preferred path has been to turn to the philosophy of social science, and in particular to social ontology (the study of the nature of social reality)... However he [Reddaway] did often impress upon me the following point. If one of my goals was to seek out and emphasise approaches to social explanation that went largely unrecognized in the discipline, it would be helpful to provide illustrations of how they work. (Lawson, 2009, pp. 405-406)

\section{Positioning Lawson's use of the concept of contrast explanation}

Lawson's account of a contrast explanation has a particular relevance within economics because it is grounded in his prior work (and that of CSOG) in response to the recognized and ongoing problems of economics. However, the notion of contrast explanation is not new, and so has meaning independently of Lawson's use of the term. This opens up the possibility that Lawson's use is relatively distinctive.

Though it has antecedents, the concept of contrast explanation is typically attributed to van Fraassen in his The Scientific Image (1980). As Michael Friedman states in his contemporary review The Scientific Image is a work in post-positivist analytical philosophy of science (1982). It is a procedural analytical argument for what science is, following the claimed failure of positivism to adequately account for the

\footnotetext{
${ }^{6}$ Where scientism broadly follows Hayek's use of the term: the inappropriate use of and understanding of scientific method for the particular purposes it is then applied to (though not necessarily involving the politicisation of knowledge that Hayek also associates with the term).

7 Though this remains controversial. Many still argue for the superiority of a given position or school either as theory or as already articulating the insights claimed via social ontology. The relation to Marxism has been one of the main foci for this debate, see Brown et al 2002, Brown 2007, O'Boyle and McDonough, 2011, Creaven, 2000.
} 
nature of (natural) science. Contrast explanation is introduced in chapter five as a general model of what a causal scientific explanation consists of. The concept is thereafter critiqued, defended and developed in various ways within analytical philosophy (notably by Lipton, 1990; Hitchcock, 1996, 1999; and Botterill, 2010). Garfinkel (1981) also introduced the concept of contrastive question forms at about the same time as van Fraassen. However, his concerns were rather different, focused more specifically on issues of social theory. Again, this work has been variously critiqued and developed within social theory (beginning with Hollis's review in 1982).

Both van Fraassen's and Garfinkel's work have been drawn on in subsequent discourse regarding the nature of causation and concerning the problem of what there is to explain. This has become part of discourses of the nature of theory and method in a range of fields; for example, in international studies, most recently in works by Grynaviski (2011) and Humphreys (2016; cf. Patomäki 2016). It is important to note, therefore, that contrast explanation is not original to Lawson and nor is it tied to a given position in philosophy or to social ontology. ${ }^{8}$ Setting out key aspects of van Fraassen and Garfinkel's work provides a useful comparative way to situate Lawson's account of contrast explanation in and for economics.

\section{Van Fraassen: contrast explanation within the philosophy of science}

In The Scientific Image van Fraassen sets out to reconstruct how natural science is conceived. Specifically, he sets out to refute both logical positivism and its variants and scientific realism, and in so doing, make a case for a pragmatic or 'constructive empiricism'. His core claim is that science seeks to explain facts and events. However, merely to state that theory $T$ explains fact $E$ does not itself imply theory $\mathrm{T}$ is true, will continue to be empirically adequate and will thereafter always be acceptable. Many theories over time have satisfied the statement theory $T$ explains fact $E$, but have ultimately failed to be true, empirically adequate (since anomalies and contexts in which they fail arise) and accepted (they have been rejected, superseded, encompassed by other theories etc.). For van Fraassen this means that scientific realism cannot be an adequate account of science, since such realism requires that an explanation is true and science aims to find true theories (a position he associates in particular with Hilary Putnam). ${ }^{9}$ Instead, one can only state 'that we have an explanation is most simply construed as meaning we have 'on the books' an acceptable theory that explains' (1980, p. 100).

To be clear, the implication is not that theory is and can be entirely false or irrelevant, merely that the definitive truth of theory is not established by science. Science is most appropriately conceived in terms of 'the basic relation of explanation, which may be said to hold between facts relative to a theory, quite independently of whether the theory is true or false' $(1980, \mathrm{p} 101)$. As such, science is focused on the continual establishment of the empirical adequacy of what can be observed (1980, p.

\footnotetext{
${ }^{8}$ Note, Lawson is clearly aware of this, since he references Lipton in Lawson, 1997, and van Fraassen, Lipton and Garfinkel in his 2009 paper (and briefly in Lawson, 2003). However, since his focus is to develop his own work on contrast explanation he does no more than acknowledge that 'various aspects of the account defended here are paralleled in writings elsewhere' (2009, p. 408). In addition to 'various' and 'parallel' the difference is also instructive for the significance of social ontology.

${ }^{9}$ We put aside the critique of logical positivism, since the realist critique is more germane for social ontology and Lawson's work.
} 
151). This weakens its epistemic commitment to no more than that a theory is empirically adequate if it can be established that it fits what is observed (and one can remain non-committed to the truth of the unobservables expressed in theory). So, whilst not reduced to what is observed, the fulcrum of science becomes what is observed, and the status of the practice of science remains conditional and contingent - hence pragmatic or constructive empiricism. At the same time, since the purpose of science is to explain, it is the nature of explanation that must be reconstructed by the analytical philosopher (in the aftermath of logical positivism and scientific realism). It is here that van Fraassen begins to introduce contrast explanation.

According to van Fraassen 'science gives a picture of the world as a net of interconnected events' (1980: p. 123) focused on explanation where (1980, p. 124):

1. Events are enmeshed in a net of causal relations

2. What science describes is the causal net

3. Explanations of why an event happens consists (typically) in an exhibition of salient factors in the part of the causal net formed by lines 'leading up' to that event

4. Those salient factors mentioned in an explanation constitute (what are ordinarily called) the cause(s) of that event

For van Fraassen $1 \& 2$ concern the general structure of causation. In The Scientific Image he has relatively little to say about this other than to suggest, in accordance with use of the terminology of a 'causal net', and a focus on 'leading up' to an event, that science investigates causal relations as complex causal processes, and that these can be conceptualised as a spatio-temporal continuous series of events. Explanation then becomes an intervention into the continuous process. ${ }^{10}$ The nature of the intervention is the subject matter of $3 \& 4$ and it is these with which he is primarily concerned: the development of a general framework for how scientific explanation is structured.

For van Fraassen, an explanation follows from a why question. Any meaningfully stated why question for explanatory purposes has two key components (1980, pp 124129). First, it has a position or context dependence, which shapes the question form as an explanatory investigation. So, a mechanic, a lawyer and a doctor would pursue quite different aspects and emphases in regard of a death in a motor accident (the cause of interest and statement of that cause could be: a defect in the breaks, the negligence of

\footnotetext{
10 Note, much of van Fraassen's approach here is a reconstruction of W. C. Salmon's work. The most notable feature of the approach for our purposes is that the overwhelming focus is on causation and events. However, there is no proper distinction made between what causes events and a continual production of events that are caused (are events merely the product of events?). The problem is not that van Fraassen's work is incompatible with a complex structuring of the grounds of events, but rather that he has little to say about what the distinctions may be. In one passage he distinguishes real and pseudo processes: so, the location of a car is a consequence of its motion as a continuous series of events, and this is a real process (where it has been is responsible for where it is going to be), but the shadow of the car is not a product of where the car has been, but rather of where the car is now and the location of the sun the shadow tracks the car, but this is a pseudo process. In another passage, whilst providing a constructive critique of J. L. Mackie's (1965 and 1980) INUS, he notes Aristotle's typology of causation is not central to modern theories of causation, yet later he draws on the typology (without endorsing the metaphysics) to support his own argument for positioned contrast explanations, where he also notes there is some structure of causation to be accounted for $(1980$, p. 131). Ultimately he resists making any claims or drawing any inferences about the structure of causation since this might weaken his claim that science can make no claims about reality through its use of theory, and that its appropriate focus is empirical adequacy of observables (constructive empiricism). See later comments on ontology.
} 
the driver subsequent to the vulnerability of the breaks, or severe head trauma). This creates a conditional relevance for investigation within which salient factors are selected. Second, the why question form, at least implicitly, involves contrasts in terms of specifying possible alternatives to $X$ happening, providing a 'contrast-class'. ${ }^{11}$ It is by exploring the particular case, based on the context (positioning and purpose of the participants in the investigation), and through a selection of contrasts (of what happened informed by the context) that one identifies the causes for what did occur (with reference to what could and did not).

One might be tempted here to infer that van Fraassen's account of explanation is judgmentally relative, in the sense any and all answers are accepted purely because there can be different positions and answers. However, contrast explanation is intended to be intrinsically relative but not judgmentally relative. He remains committed to the possibility of objectivity regarding evidence. Van Fraassen's purpose is to establish that any investigation of actual events, where an explanation is sought, must be positioned and involve a contrast-class (1980, p. 129). A god-like being with access to all information about any given event would still require a positioned and contrastive question form in order to state an explanation of that event. Why did $\mathrm{x}$ occur as it did rather than y can only meaningfully be answered from positions (e.g. doctor, lawyer, mechanic) and can only make sense in terms of the unfolding of events in time. The only difference god-like status would confer is the capacity to construct any and all relevant explanations from any and all positions based on determinably good information or evidence.

Van Fraassen's aim is to set out criteria for what an explanation is, subject to the analytical structure of a question (1980, pp. 141-152). Within context and based on contrasts, an explanation invites an answer. ${ }^{12}$ For that answer to be accepted (to be considered an adequate direct answer) the explanatory factors selected must be relevant, they must be subject to evaluation and they must be accepted as good. Van Fraassen (1980: p. 126) argues that 'no factor is explanatorily relevant unless it is scientifically relevant; and among the scientifically relevant factors context determines explanatorily relevant ones'. It seems curious then that the development of the concept is illustrated through socially situated examples (doctor, mechanic etc.). ${ }^{13}$ In any case, at this point van Fraassen returns to his primary argument, that science is concerned with the establishment of the empirical adequacy of what can be observed. The role of theory is

\footnotetext{
${ }^{11}$ Note, clearly van Fraassen is not asserting that all questions are why questions or that all why questions are followed by causal explanations (why is 6 even and 7 odd need not invoke a causal explanation). His focus is on the general expectation in the use of terms in scientific discourse. In social science all kinds of responses may be evinced by questions - moral issues etc and these may be non-causal accounts. Note also: there is some ambiguity in terms of van Fraassen's use of the term concept-class, since the contrast could be the different ways in which an event could have occurred whilst still being investigated from a given position - and so the contrast class may be either alternatives to the event that occurred or alternative narratives of causal processes leading to the event that occurred. At some points in the text van Fraassen seems to mean one or the other of these. The combination markedly complicates the application of contrast-class approaches, since it multiplies with few limits the potential for contrast classes to be formulated. Moreover, the latter of the two meanings blurs into the claims about intrinsic aspects of the causes responsible for the event, and as such leads towards Botterill's 2010 distinction (see later).

12 Though the statement sounds silly when stated like this, as a developed argument the point is to distinguish between a proposition or hypothesis and an answer.

${ }^{13}$ In general, the majority of actual examples provided are everyday situations within society, combined with archetypical problem sets (paresis-syphilis, the flagpole etc), rather than fundamental problems of well-known natural science theories. The latter may require context but this is very different as an issue for theory legitimation than it is for practical applications for a doctor, lawyer or mechanic (Friedman, 1982. p. 281).
} 
to inform pragmatic investigation. This raises the question of what is meant by theory. Van Fraassen's core claim is that science seeks to explain empirically observed facts and events. In many of his examples van Fraassen seems committed to the event regularity view of scientific theory. What matters is empirical adequacy, not truth. Science is focused on the continual establishment of the empirical adequacy of what can be observed (1980, p. 151). This implies, among other things, that we should be agnostic about unobservables. ${ }^{14}$ Moreover, for van Fraassen much of science is probabilistic and covered by standard frequency-based statistical approaches.

As one might expect, once the concept of a contrast explanation had been introduced into philosophy of science others began to explore its limits within that discourse. For example, Lipton (1990) phrases the contrast as that between a fact and a foil and then addresses the problem of reduction where, instead of why $x$ rather than $y$, one can separate out and have merely why $x$ (and a distinct why not $y$ ). ${ }^{15}$ Lipton argues that there is a link in the practice of explanation between why $x$ and why not $y$ because of a 'difference condition': there is a cause in the causal process for $\mathrm{x}$ that is (or would be) absent in y. Identifying this cause becomes part of inference to the best explanation, which in turn enables claims of explanatory success, which in turn provide a warrant for theory that informed the investigation.

However, as Hitchcock $(1996,1999)$ then argues, if one applies a contrastive question form, where a given cause makes the difference, then one becomes open to the critique that determinism applies $(1999$, p. 595). Yet in introducing the original term van Fraassen argues towards a probabilistic account of cause and as Hitchcock notes, Lipton's version fails to properly differentiate deterministic from indeterminist situations. ${ }^{16}$ Hitchcock then sets out to refute a 'contrast explanation implies determinism' (CEID) thesis (1999, p. 586) on the basis that it is too restrictive and follows more from an unjustified expectation of what science can achieve. Finally, Botterril (2010) shifts the focus to the problem of explanation as an intervention into a causal process. Specifically, the requirement to explain invokes, via David Lewis, Mill's 'problem of limitation': if any given event (or phenomenon) has a causal history then intuitively the more of and longer that history (possible conditions of the event) is expressed in the explanation (the answer) then the better the explanation (as Mill puts it: the 'real cause is the whole of the antecedents' cited Botterril, 2010); yet science must select and must limit according to some criteria and some demonstrable consequences, in order to be science. According to Botterril, relevance and adequacy guide investigation and there are two types of questions one might pursue: contrastive why questions and descriptive-as-explanatory how questions. Here, Botterril goes some way to reproducing the decomposition Lipton wants to refute (why $x$ separated from a why not $y$ ). However, Botterril is clear that why and how are differentiated by emphasis and separated as a matter of degree only. A how question provides a tighter focus on the

\footnotetext{
${ }^{14}$ In our view, there is a lot of confusion about this debate about unobservables. Observable is not reducible to what can be seen by eye, one can observe by trace or response etc. The more we allow for theory, interpretation and technology in "observability", the more we can observe. For instance on 14 March 2013, CERN confirmed that they are likely to have observed a Higgs boson. See Patomäki, 2014.

${ }^{15}$ Following standard philosophical nomenclature and practice $P$ not $Q$ is used. Since Lawson uses $\mathrm{x}$ and $\mathrm{y}$ we have altered the symbols to ensure consistency. The originals contain theorems stated in standard set theoretic form which the reader can consult for a sense of the framing of the discourse: a critique of logical positivism etc, but one that remains within the same modes of expression and sympathetic to many of the goals. See further comments.

${ }^{16}$ Indeterminist is taken to mean that events could still be otherwise despite the factors expressed in the causal history, and this can then be stochastic.
} 
specific mechanisms that are responsible for the event rather than the elimination of those that did not.

\section{The limits of analytical philosophy of science and the implications for ontology}

Setting out the material here seems to have taken us some way from a direct concern with economics and also with Lawson's work. However, that is the point. If one considers the above then the terms of argument and thus of development of contrast explanation have particular limits. Contrast explanation is developed as a solution to longstanding issues in philosophy of science. In this development, contrast explanation is not a method per se, but rather a claimed structure of what a question form must look like as part of a scientific investigation. For van Fraassen such investigation cannot be conceived in logical positivist terms. However, the structure of argument in The Scientific Image is also specifically set out to refute a particular conceptualisation of scientific realism and to focus significance on observable events. So contrast explanation is situated as empiricist and the mode of argument is set out using analytical philosophical methods - including expression in symbolic logic (an approach conducive to the use of theorems and demonstration proofs - something participants to the discourse variously apply when considering the coherence of contrastive questions). Moreover, as Michael Friedman notes, van Fraassen remains quite close in method and sympathy to logical positivism, including in chapter 6 based on probability theory (1982: p. 275).

One might, of course, simply state that Lawson's work is quite different from this. However, the implicit point is that the potential value of contrast explanation may be because of that difference. Consider again the general characteristics of the above: a philosophy of science pragmatic approach to theory (with a framing that continues to be influenced by the positivist position it tacitly rejects), based on potentially narrowly stated contrastive question forms (connecting together continuous flows of events), expressible in terms of symbolic logics and pursuable subject to probability. It is not difficult to imagine how van Fraassen's contrast explanation could become part of current mainstream economics with little impact on the general tendencies of that economics (or of its subdisciplinary philosophy of science focus). It involves a framing that continues to be tacitly influenced by the positivist position it explicitly rejects. It is based on contrastive question forms aiming to connect together continuous flows of events. It is expressible in terms of symbolic logics and pursuable subject to probability implying stable frequencies. One should also note here that van Fraassen says little about the characteristics of the content of theory - particularly in terms of unobservables - and so one could easily infer that theory can reasonably include assumptions as idealizations, or axioms as analytical constructs, as long as the whole then passed (or at least pursued) some test of observables. To adopt van Fraassen's work within economics based on all of the above would probably be to do a disservice to his overall intent and that of subsequent contributors (see van Fraassen, 2008). But that is neither here nor there in terms of the potential.

Notably, van Fraassen's way of introducing contrast explanation potentially breaks the link between a critique of scientism and a realist alternative in the social sciences. Recall that van Fraassen positions scientific realism as the claim that science aims to find true theories and true explanations. However, actual theory and explanations are accepted as good at some point in time, but subsequently rejected or superseded. Based on the demonstrated impossibility of definitive non-trivial truth claims, van Fraassen develops an account where explanation is relative to theory, and 
explanation is positioned by both context and the findings of investigation. As such, the whole is conditional at a point in time and contingent through time. This is then used to argue for an observation-focused empiricism. However, despite van Fraassen's critique of scientific realism that critique does not amount to an adequate refutation of philosophical realism (an ontology), but rather of a specific epistemic claim about absolute or fixed truth claims. Quite apart from whether van Fraassen's approach to scientific realism is a reasonable interpretation of Hilary Putnam's work (see Groff, 2004; Norris, 2002; Chakravartty, 2007) one can also reverse the line of reasoning. One might argue that it is an epistemic fallacy to use the fallibility of theory to reject that theory is of the real world (is meaningfully real world oriented), and so realism (not definitive truth claims) is representative of what science seeks to do and can achieve. ${ }^{17}$ Moreover, it is precisely the conditionality of theory and the contingency of claims in and through time that make ontological realism relevant. This has been a key insight advanced by Lawson and various others via CSOG.

Because reality is irreducible to any existing theory one can defend epistemological relativism. But without ontological realism there would be no sense to the scientific process at all, since there could be no currently adequate conditional claims for how things are. There could be no possibility of artificially isolating conditions to produce regular relations, and no way of using insights about these to help make things using 'how things are', and help shape things based on 'what could be' based on how things can be made to happen. Fundamentally, there would either be nothing to ask a contrastive question of the form why $x$ rather than $y$ about, because there would always be either $\mathrm{x}$ or $\mathrm{y}$ as a regular outcome, or there would be no point in asking the question because nothing learned in the given case would inform any future intervention in the world, since there would be nothing to relatively consistently cause outcomes. So, from an explicitly ontological position, much of van Fraassen's account seems to be vulnerable to realist counter-critique, where the most plausible claims made are actually supportive of a variety of ontological realism. That is, based on truth seeking regarding a real world that is differentiated, structured, layered, causally efficacious, open-systemic and so on, rather than truth identity as a required characteristic of the rationale of truth seeking.

The reversal of van Fraassen's position makes it clear that the terms of explanation require more to be said about the nature of causal-processes. Arguably, it is the powers, capacities etc. of aspects of reality, which produce events and processes. It is these aspects, which give meaning to 'why' questions. This extends from the natural to the social sciences and to economics. It is insufficient to claim that a causal network of events predates any given event, since this says little about whether reality is no more or less than a continuous series of events; one shifts from an agnosticism in terms of theory to a significant lacunae in how one conceives of the structuring of reality from which events can arise. Van Fraassen's work, can thus illustrate the importance of ontological argument and of developing concepts within this domain of argument, something Lawson does. In van Fraassen's case one ought also to emphasise its focus is mainly philosophy of science rather than implications for social science. ${ }^{18}$ This also is

17 An epistemic fallacy is where one collapses issues of ontology (what may be) into issues of epistemology (what and how things can be known)

${ }^{18}$ Again, to be clear here, van Fraassen positions much of what could be ontological argument in terms of the structure of causal processes (1980, p. 124) and then sets this aside. He states that there are continual casual processes of events, and then says almost nothing about the differentiation of causes from events (so causes may simply be prior events rather than the powers of things that are exercised through intrinsic and extrinsic relations). This is a strategic move in order to support his constructive (pragmatic) 
important, because if the events, outcomes, situations and so forth to be explained are produced, then the nature of the reality that produces them is a significant issue for the scope of explanation. Any science of society must have a sense of what is particular to society that affects what there is to explain, and how explanation can be appropriately pursued. As a general work in philosophy of science, van Fraassen has little to say about this. However, Garfinkel's work on contrastive question forms is more specifically focused on issues of ontology and social theory. As such, it provides a further useful point of comparison we might then use to position Lawson's approach to contrast explanation.

\section{Garfinkel: contrastive questions and structure in the social sciences}

Like van Fraassen's, Garfinkel's work also has a particular position and purpose. Though Garfinkel ranges across philosophy of science and social science, Forms of Explanation (1981) was written to refute reductive individualistic explanations of social phenomena and the ideological role this has played through its association with valuefree claims that illegitimately justify value-laden social outcomes. He argues that biological or psychological accounts of social activity are typically insufficient. They are micro-level. However, activity does not just have a micro-level but also a macrolevel or context. It is socially relational and structured. One can explore localised contexts but can continue to extend to broader and different frames of reference. Contrast explanation is introduced as a way to make sense of this.

As with van Fraassen, for Garfinkel any non-trivial why question requiring a causal answer involves at least an implicit contrast. For example, a student is a member of a class, the class is graded according to a distribution. Therefore, what a student achieves as a grade is relative to what others achieve. If the assessment is an exam, one may be assessing individual content, but the assessment is a context subject to conditions. It would be a partial and inadequate explanation to claim a student achieved the top grade merely because he or she was intelligent. This achievement is also based on comparisons and collective constraints such as the norm of normal distribution of grades. As such, one might ask: Why did student $x$ achieve an A rather than student $y$ ? Thereafter, as van Fraassen also does, one can continue to add additional questions based on different ways of considering the problem of explanation. These are 'contrast spaces' (1981, p. 40). For Garfinkel, contrast explanations can assist in making it explicit that social realities are usually relational and involve emergent properties in various ways. Moreover, actors and activities are not relational merely in a localised sense that each event had a set of specific or local enablements and constraints that structured it. Garfinkel's concern is broader than this.

Forms of Explanation is a critique of 'value-free' social science. Examples such as how one grades a class are used to indicate that contrast questions are at least implicit in any explanation of 'why' things happen. But the argument is also made that one can continue to shift the perspective of questions, and also expand the bounds of what is to be explained. Unlike van Fraassen, he does not simply consider that there are differently defined concerns for positions, based on examples such as doctors, lawyers, mechanics

empiricism focused on explanation. As Friedman then also notes, the focus on weakened epistemic commitments via observables seems overly restrictive - no reason is given for claiming theory and empirical work trade purely on observation, and van Fraassen has little to say about the core issues that a theory of science actually provokes: what is the implication of and nature of justification for rational belief in a real world where not all is observable. 
etc; there are also broader analyses of the role of each participant in a relational context. For Garfinkel this reveals that social outcomes are value-laden and causal explanations are value-oriented (what is justified, just, preferred, deemed acceptable etc). The corollary is a critique of varieties of social science that proceed as though they were not value-laden and value-oriented. For Garfinkel this includes positivist social science that seeks to emulate an image of the natural sciences. In particular, he focuses critique on reductively individualistic accounts that place overwhelming emphasis on underlying invariant behaviours and traits, where those invariants are allowed to stand as adequate final explanations of the nature of society and of its outcomes.

Garfinkel's main focus is the problem of income inequality within societies. For Garfinkel, individualism justifies and hence perpetuates social problems like inequality by serving the function of attributing blame and praise. Individualistic accounts imply that the distribution of income is in the end determined by individuals' given natures, characteristics, capabilities and effort. These kinds of explanation are to a large extent legitimising justifications for the existing distribution of wealth, power, and status. They exercise moral authority. Garfinkel positions his own work as a form of ethically naturalist anti-positivist social science, emphasising the need to justify the explanations one provides, and the broader consequences of the societies they are indicative of (and so also the inherent values).

According to Garfinkel, structural explanations using contrastive questions in more encompassing contrast spaces will tend to bring to the fore underlying or more stable sets of causes, and so bring into sharper relief issues that are otherwise obscured. Concomitantly, his argument is not just about the importance of values, it is also explicitly political as a critique of free market ideology (notably focused on Nozick). It is value-based.

\section{Social ontology, social theory and claims about reality}

Garfinkel introduces contrast explanation in an overall argument that creates notwithstanding its many insights - potential grounds for misunderstandings that social ontology in economics sets out specifically to avoid. Critique of Garfinkel's work has oriented on its preference for macro-level explanation as though this entailed the individual no longer mattered (which surely was not his intent). It is an empirical matter whether macro-level explanations (or causes within causal complexes) are more significant (Webb, 1983, p. 816; for other early discussions on Garfinkel, see Turner, 1984; Hollis, 1982). Garfinkel's work has also been inadvertently vulnerable in so far as it blurs various distinctions as an argumentation form. From a realist perspective it tends to blur the distinction between ontology as a domain of argument, realism as one set of arguments within that domain, and what is specifically real as a claim about the world. ${ }^{19}$ Social ontology in economics has approached this slightly differently in order to emphasise the distinctions and so avoid misunderstandings, some of which are particular to economics (see Lawson, 2003; Pratten, 2015). The work of Lawson and CSOG developed in response to the multiplicity of heterodoxy and the recognized oppressive strictures of the mainstream. As such, it has developed in a discursive context that has required sensitivity to pluralism, whilst maintaining a critical orientation via ontology that argues also for some kinds of commonality. Garfinkel's work is not positioned in this way and is not an explicitly ontologically posed position

${ }^{19}$ Forms of Explanation is not a work on ontology. It might be categorised as pragmatist. However it has clear realist family resemblance and Garfinkel was a student of Hilary Putnam. 
and so does not make similar distinctions in the way contrast explanation is introduced and pursued.

Based on Lawson's work social ontology is firstly a domain of argument. One raises questions about what characteristics, conditions, capacities etc. are implicitly or explicitly required or implied for theories and methods to be effective or justified. There can be many different approaches to social ontology and many different approaches to what is effective and what is justified. In this sense an argument for social ontology is no more or less than the claim that one cannot avoid having an ontology so it is reasonable to explore what its terms are. The domain is an invitation to debate and dialogue. At the same time there can be general arguments for an ontology or theory of being, and then more specific versions or applications of the same. One might make a case for a variety of realism and do so in terms of general concepts such as agency and structure, or specific contexts such as gendered agency or money or the corporation. This is ontology as specified theory. It creates issues in terms of the link between realism as philosophy and what is real based on substantive claims. Without these the whole becomes vulnerable in a different way - unresponsive as some form of Lakatosian hardcore. The issues are not irrelevant for general philosophical claims regarding an ontology, because any form of realism must involve demonstrable claims about the nature of reality, but this is a different order of argument than whether ontology has merit as a domain of argument (since theory etc. has at least a tacit ontology).

The point here is that maintaining the distinctions (ontology, realism, what is real) is important, but creates significant grounds for confusion, since there is a tendency to integrate claims such that: this theoretical position, this explanation based on these methods is both realistic and well justified (and so the best account of - this aspect of reality). Clearly, there is nothing wrong with making such a claim, without such claims explanation ceases to be a meaningful enterprise. It remains the case that ultimately theory should be judged as theory and based on its explanatory success or failure - so it may actually be the case that a post-Keynesian or Marxist or an ecological economist has 'the best on the books' account subject to justification which others may be persuaded of. Moreover, when the underlying practices change, so must our philosophies and social theories. In this sense, in the long run philosophy must be consistent with the findings of science (see Patomäki, 2010). However, analytically a distinction can still be made between ontology as a domain, realism as philosophy, and what is claimed to be real and this distinction has been an important one within economics because of the recent history of the sociology of knowledge within economics.

If distinctions are not carefully stated then ontology can claim too much because an ontology expands to fill the domain of ontology, and in so doing may deploy the language of 'realism' to position any subsequent work as more realistic and so a priori 'correct' - creating a problem of presumption that insulates a discourse from proper critique - providing its adherents with a dangerous sense of mission and certainty (not least by confusing philosophy with social science rather than recognizing one feeds the other). This does not have to be an intent nor does it have to be a fully accurate description of a state of affairs for the possibility to be damaging. It can involve (mis)inference by interlocutors. Despite being about multiple positions, Garfinkel tends to collapse together all aspects of an ontological argument in his development of contrast explanation. He does so partly because his argument is not also positioned as ontology. This does not invalidate any of Garfinkel's substantial arguments. But it does highlight, a difference of degree in how Lawson's work has developed and been 
articulated within the context of economics. One might suggest that its problem field has influenced the strategic shape of realism as social ontology in economics. However, Lawson's work cannot be reduced to mere instrumental strategies of intervention for that field.

Lawson has repeatedly made it clear that his work is not a replacement for particular schools or theory, and is not exclusively aligned with a particular approach or method (1997, 2003). As ontology it is part of an open discourse for dialogue and debate, and as a philosophical position (a social ontology - realism) it serves an 'underlabouring' function. However, as social ontology it also explores the nature of aspects of reality, as it is claimed to be (particular institutions, corporations, money etc.), and so can involve more or less substantive claims. It is in this latter sense that Lawson positions his own use of contrastive question forms. They are positioned as an explanatory approach to what is posited to be real, a further step into the realm of social science. The social ontology provides the grounds for consistent application of contrast explanation in the social realm (related to economy), but the ontology also includes explicit distinctions, such that one does not inadvertently blur the difference between ontology, realism, social theory and claims regarding what is real. Instead the conditionality and contingency at every stage continues to be emphasised.

For van Fraassen and Garfinkel, contrastive questions are part of the general framework that any well-stated causal explanatory investigation must take. For Garfinkel contrastive question forms are also basic to the argument for why society is relational (the demonstrated relevance of relative relational contrastive question forms establishes something about society, and particular applications then demonstrate the superiority of contrast spaces extended along macro-state structural lines). For Lawson, contrast explanation is more modestly stated as one possible way to approach investigation of social reality (aspects of an economy). ${ }^{20}$ However, the form a contrast explanation takes is intended to be consistent with the social ontology he has previously developed. As we set out below, this cannot prevent there being some issues of ambiguity in Lawson's development of contrast explanation. On the other hand, as we also illustrate, the general consistency flowing from Lawson's social ontology does stand in stark contrast to the potential misunderstanding of the scope of explanation and investigation that continues in the mainstream.

\section{Lawson on social ontology}

In the previous sections we have set out van Fraassen and Garfinkel's work on contrast explanation. Van Fraassen says little about what would be particular to society that would then create grounds for how contrast explanation should be deployed. Garfinkel is more specific in terms of the nature of things that can be explained and how they might be explained. For him the point of contrastive questions is to explore our presuppositions defining the boundaries of the realm for which the explanation holds. It is not only that we need to limit negation and create a determinate sense of what will count as the consequent 'not' happening ( $\mathrm{x}$ rather than $\mathrm{y}$ ), the point is also to specify the kind of thing for which an explanation can hold. "B-ness will explain A-ness only for the kind of thing that X is." (Garfinkel 1981, p. 30-9). Garfinkel opposes reductionism

\footnotetext{
${ }^{20}$ Also Lawson notes in Reorienting Economics that Garfinkel's use of contrast explanation is applied and focuses mainly on known causes rather than seeking unknown or previously unconsidered unobservables (Lawson, 2003: p. 309).
} 
and individualism, especially in social sciences, and stresses the relational nature of many social and other phenomena.

While in agreement about the relational nature of society, Lawson's use of contrast explanation is somewhat different in so far as it flows from his approach to social ontology. When the explanandum $\mathrm{X}$ consists of events (such as price movements or quantities of materials or outputs), then typically the only patterns that can be found are partial and unstable demi-regularities. This is due to the openness of social systems. From a causal explanation point of view, the underlying structures and conditions are more important than the empirical patterns only. This implies a distinction between events and what causes events (something that is ambiguous in van Fraassen's work, but does not place overwhelming emphasis on macrostate explanation as one might infer from Garfinkel). For Lawson a mechanism is a way of acting or working of a structured thing. He argues that a fundamental role for contrastive explanation is identifying causal mechanisms in open systems.

Lawson develops an account of emergent layers of reality and a social ontology that makes sense of causation at the emergent level of society. Causation arises from social activity based on the powers or capacities of a range of relevant entities. Entities are real in so far as they have capacity to bring about causal effects (this is the realist causal criterion of existence). Causation is conceived along broadly Aristotelian lines to also include material cause as well as effective cause, and so includes the conditions of possibility of any activity as well as the active agent of any particular event. Society and economy are historical and spatial, cumulatively shifting causal processes.

Emergent entities are real, and both causally and ontologically irreducible to the elements relationally organised as components, since the organising structure also matters; without the (particular) organising structures (that are external to the elements organised as components) there would be no (particular) emergent entities. Here, Lawson's social ontology clarifies what is left unexplored by van Fraassen. Social reality crucially includes emergent sentient entities (us) that produce and reproduce society around them in multifaceted ways, and the society that is produced and reproduced includes other emergent entities, which in turn position, constrain and enable the activity of people. Those entities range across recognizable sets of bounded relationally organised totalities positioned under various legal and other descriptions, generically referred to as communities (involving rights and obligations), such as limited liability corporations. From this point of view, there is a single multi-form and multi-level reality, including social reality, and, as such, any adequate attempt to theorize and investigate that reality must both be aware of commonality and difference. From the point of view of Lawson's social ontology an adequate economics is differentiated by focus and emphasis from other social inquiry, rather than by any radical difference in its object of study. This does not prevent economics being a (branch of) social science, when science as practice is appropriately conceived.

For Lawson, there are many participants within a society, many different positions, interests and goals, and many possible ways in which a society may internalise principles of social activity directed at change, perhaps within discourses of progress and development. These in turn involve different consequences for change in so far as principles can be inherently more divisive, competitive and disintegrating, or conversely more cohesive, cooperative and integrating. There are also differences and intra- and interactions between specific societies within the wider whole of the global capitalist economy. This evolving complexity makes relative stability, under a deeper description, quite different from regular connections between things or events. Again, 
for Lawson social reality is, as stated, recognizably a historical and spatial, shifting cumulatively causal process.

Clearly, much of the above resonates with claims made by many prominent nonmainstream economists over the decades. The ontology has been sufficiently general to act as supporting argument, when specified, for work drawing on Keynes, Marx, Veblen, Hayek etc. extending all the way to ecological economics (since it is implicit to any adequate account of social ontology that an emergent social reality is grounded in the limits of material reality), and gender (since any social relation may have some gendered aspect). However, in so far as mainstream theory, concepts and use of methods assume or are dependent on or seek to identify forms of atomistic regular relations in events, they are intrinsically problematic. They are by virtue of ontology at odds with the social world they investigate and so are questionable as a scientific project. For example, being at or moving toward equilibrium is not capable of explaining any real tendency, process or outcome in political economy, given the kinds of things economy and society are. In relatively closed physical systems, where the basic forces are stable and laws precisely measurable and expressible in a mathematical form, calculating an equilibrium position or movement can have predictive (or at least postdictive) power, but not so in economics. In economics, it is a property of formal models and a solution to a system of equations, with limited connection to the real world. ${ }^{21}$ Following this critical social ontology Lawson introduction of contrast explanation is relatively straightforward.

\section{Lawson on contrast explanation}

For Lawson, the primary goal of science, natural or social, is to identify and explore (with a view to explanation), the causes of phenomena of interest (Lawson, 2003, 2009). Whilst others also accept this goal, the open and complex nature of social reality usually encourages the view that one must simplify in the sense of employing accepted-asunrealistic assumptions. These assumptions deform the essential internal and causal relations of the actual complexity that one intends to investigate. The tendency to so proceed is exacerbated if one conceives of science as a search for law-like underlying regularities (strict or stochastic) of events. For Lawson, instead, contrast explanation can be used to inform a more adequate and nuanced investigation that can concern itself with real causal processes that occur in time and space. Contrasts are important in prompting the investigation and in revealing what may be significant:

Rather than to seek to explain some outcome $\mathrm{x}$, the goal is to explain some contrast ' $x$ rather than $y$ ' and to do so in conditions where we might have expected the contrasted outcomes to be the same, because, as far as we could discern, they shared the same causal history. The approach thus turns on

\footnotetext{
21 When the term "equilibrium" is discussed in the language of economy, it has many competing meanings. Equilibrium theorists in economics do not know what an "efficient equilibrium" would designate in the real, concrete world (outside their abstract models). Even if there were a concretely specifiable equilibrium in some sense in a given market, neoclassical models would have nothing to say about how to get there. Besides, if an acceptable specification of a market allows for one equilibrium, it will typically allow for many. Even if the specification of the market were based on realistic assumptions, any of these equilibria would be Pareto optimal, and if there were a clearly specified way of getting there-none of these conditions are usually fulfilled and in all likelihood can never be fulfilled - these models say nothing about whether efficiency in, say, the financial markets would actually enhance the efficiency of the economy as a whole. (Lawson 1997, pp. 86-92; 2005).
} 
explaining differences in outcomes, but differences that, from the point of view of existing understandings, are considered to be surprising, noteworthy, inconsistent, disturbing, doubt-inducing or otherwise interesting. (Lawson, 2009, p. 407)

Clearly, the phrasing here is broad in terms of what provokes an investigation (see Morgan, 2013). In a formal sense there seems some ambiguity between a contrast question that is recognized for the purposes of explanation, why x occurred rather than $y$, and what kind of anticipation results in the focus, since the scope for varieties of $y$ that make $\mathrm{x}$ stand out seems great. For example, must $\mathrm{x}$ be different than what has previously occurred, and so rather than refers to what is different by observation ( $\mathrm{x}$ is different from y that occurred previously, and one might anticipate y), or can $\mathrm{x}$ refer to something that did not change, where one anticipated change, and so rather than refers to what is the same by observation ( $\mathrm{x}$ is different from $\mathrm{y}$, but $\mathrm{x}$ is what occurred previously and one anticipated $y$, which did not occur now or previously)?

The question then becomes, what conditions are conducive to the identification of aspects of causal processes? For Lawson, if one is to explore a causal process then the most conducive environment will be where our best understandings lead us to expect, over a specific space, similarity of outcomes of two phenomena within the space. $^{22}$ Under such conditions there is reason to suppose that where expectations are contradicted, the relevant difference can be accounted for by only one (or at least a small set of) factor(s). The contradiction of expectation gives sense to his use of 'surprise'. To be surprised presupposes a level of understanding, a contrast (with what was expected, and a (set of) outcome(s) and relations on which that expectation was $\underline{\text { based). These in turn provide an implicit contrast space. Curiosity draws us to such set }}$ ups. $^{23}$

So a contrast question 'why $\mathrm{x}$ rather than $\mathrm{y}$ ' is pursued where environments involved are believed to be similar if not the same. This, when formally designed, (and with the introduction of a single controlled change) is the basis of natural scientific laboratory experiment. As Lawson notes, this is a special case: one creates a highly controlled environment in order to isolate and manipulate causal powers to demonstrate a reproducible effect (where the power can manifest through a consistent relation). However, this kind of experiment is rarely possible in open systems. Instead, one can start from surprising outcomes or more generically one can look for conditions where 'causal histories' provide grounds to expect that outcomes will be similar. So, one can look for a local relative closure (of 'concomitance') in which one would expect the same outcomes, events, tendencies etc. to continue, or look across localities in the same way. The more similar the causal history is expected to be then the more aligned one would expect phenomena to be, and, in principle, the easier it might be to orient on a particular cause of any arising difference.

When stated in the abstract the basis of contrast explanation seems simple and highly reasonable. There is a context of comparison within which differences are believed to be limited in some way conducive to the investigation. Whether differences

22 Thereafter, of any actual one with all the remaining, or with a (rough) average or with a specific other; this may be over time or at a point in time, apply to a specific form or its absence, and so on.

23 For Lawson, contrast explanation is seen to be operative, if implicitly, at all levels of social life. This does not make it any less useful to science; a significant difference is the understandings that a scientist holds at any point, and so the potential for being surprised (by events that contradict his or her scientific understandings). Lawson does also extend the approach to contrasts that might reasonably have been held to be surprising by a specific informed observer. The approach seemingly has a multitude of applications. 
are sufficiently limited is based on a judgement about conditions operating over some contrast space. Note how this use of 'contrast space' is different to how the term is used by van Fraassen and Garfinkel. The former introduces it as the space in which multiple questions by differently positioned persons can interrogate an event, and the latter defines it as the space in which an expanding set of contrastive questions can be asked, based also on values. However, Lawson's use has a family resemblance, since it is a context in which difference is recognizably bounded. Lawson's main point is that the contrast space provides conditions that facilitate a causal investigation. The idea is to identify a mechanism or mechanisms causally responsible for the contrast.

It is worth mentioning here that Lawson's approach can address some of the motivating concerns of van Fraassen and Garfinkel. The contrasts identified depend on the position of the observer (see Lawson, 1999, p. 40). A Schumpeterian, a Keynesian, or a feminist etc., may not find a given event surprising or surprising in the same way, and so proceed in very different ways. Yet, different contrasts for a specific event X, identified by differently situated investigators, can lead to the uncovering of a set of causal mechanisms each contributing to the observed outcome $\mathrm{X}$. This is not necessarily judgmentally relative:

From the perspective of contrastive explanation theory, however, we can see that neither a plethora of contradictory voices nor a commitment to judgmental relativism is inevitable. The prevalence of many different voices, even if all are considering the same phenomenon, may merely reflect a focus upon different contrasts. The investigation of different contrasts can lead to a variety of causes being pursued and perhaps uncovered. For example, suppose we focus on the U.K. productivity record in the post-World War II period. Even if all of our observers are economic historians, each may note a different contrast to the others and so pursue a different cause. For example, one of our economic historians may notice that the productivity record in question is better than the prewar U.K. record and pursue the factor responsible (perhaps the postwar expansion of demand). Another may notice that the postwar productivity performance of the U.K. is below that of many otherwise comparable industrialized countries over the same period and ponder on the causal factor responsible (perhaps Britain's relatively unique system of localized industrial bargaining). And so on. (Lawson, 1999, p. 40)

As we noted in the first section, over recent decades economics has continued to change and innovate. Part of that change has been the rise of a discourse of field experiments, natural experiments and some use of laboratory experiment (see e.g. Leamer, 1983). This has become in recent years the 'empirical turn' and 'credibility revolution' in economics (Angrist and Pischke, 2010). Lawson's introduction of contrast spaces as a restricted locality conducive to contrast explanation clearly occupies some of the same terrain; particularly that of natural experiments (an observable context in which arising differences are limited; see Morgan, 2013). However, it does so based on quite different conceptions.

Much of the debate concerning the credibility revolution indicates a great deal of the broader debate concerning natural and field experiment has been captured by concerns regarding how to produce and test regularity. Often experiment and quasiexperiment have simply become ways to specify a space in which an econometric model and test can be applied (and in others an econometric model has become the basis of a pseudo experiment). As such, and as Leamer (2010) states in his response to the 
new credibility revolution literature, the same issues of 'con' continue to apply that inspired his initial critique within econometrics. Experiment has not become a solution to the problems in the econometrics, but rather a different way to express them: problems of control, problems of comprehensive variables, well-specified models etc continue to apply. ${ }^{24}$ At the same time, much of the work based on laboratory experiment for behavioural economics, has combined problems of genuine control with questions regarding how realistic and relevant the stated isolations are beyond the laboratory. In all cases, the problem has been typically posed in terms of transitions from internal to external validity. That is, the generalisability of the regularity-claims. What can be claimed remains subordinate to how a significant economic relation is conceived, which in turn remains mainly subordinate to how it is measured. The basics remain confused even as economics has developed. The analytical distinction between ontology, realism and what is real notwithstanding, Lawson holds that the possibility and effectiveness of experiment in science lends credence to realist ontology (2003, p.103). The aim is to isolate and then trigger a mechanism and see how it works, with transfactual implications. ${ }^{25}$

\section{Lawson's illustrations of contrast explanation and their limits}

For Lawson, the main focus of contrast explanation is the real causal powers that provide the explanation of events or phenomena of interest. He stresses that although relative closures are always local in some sense, social scientists are especially interested in exploring scenarios where the contrast appears on wide scales of time and/or space (a slightly different emphasis than Garfinkel's macrostate). Lawson provides three main examples that highlight the limits of inferences that can be drawn based on contrast explanation investigation. These can be considered in logical order for the purpose of illustration rather than chronological order.

First, in Reorienting Economics, and in the later Reddaway article he uses the example of crop yields in a field (2003). This is the point of departure used by Leamer in his classic 'con' paper (1983). According to Lawson, crop yields will tend to be similar within a field unless some given factor affects those yields: more shade, a change in soil $\mathrm{PH}$, drainage, proximity to a river etc. Second, in the Reddaway paper

\footnotetext{
${ }^{24}$ One should note here that Leamer's critique is not fundamental. He has been arguing for better tests and more stringent application of tests since the 1970s; notably the use of fragility or extreme bound tests, creating a meta-analytical synthesis approach where only a few variables survive from the many used across models for any given focus of study. This is a classic example of the problem stated in the first section: a discourse in which continual failure becomes a hallmark of the activity of science rather than a reason to acknowledge that the whole may fail to be scientific (the whole can never be perfect but we continue to pursue rigour based on the best available of these types of methods).

25 This is constitutive of the tension in ontological argument. Though ontology is a domain within which different claims are possible one then makes claims and can do so based on substantive approaches to ontology that may in turn be subjects of criticism. Note: the term 'transfactual' means that generative structures, forces and mechanisms retain their identity and mode of operation across factual contexts, although their actual effects depend on those contexts. This implies that actual causation is normally complex, which resonates with Mackie' INUS-definition of cause. This actually further enlarges the contrast space and pragmatic and value-based reasons to adopt a particular explanation. What we single out as the cause depends largely on our practical capacities and expectations of normality. For instance, normally when explaining fire, the presence of oxygen is just part of the background, but the presence of the oxygen, too, can be seen as the cause of the fire, say in a laboratory or in a factory, where special precautions are taken to exclude oxygen (Mackie, 1980). All INUS conditions are real and implicate real powers (structured entities with the power or tendency to manifest particular characteristic properties $\mathrm{X}$ and produce outcomes $\mathrm{O}$ ). Indeed, what makes the relevant difference depends very much on the context.
} 
Lawson (2009) reconstructs Akerlof's (1970) 'market for lemons' argument concerning adverse selection and information asymmetries. Third, in Economics \& Reality, he discusses the already noted case of Britain's relatively low rate of productivity growth from the late $19^{\text {th }}$ century to the 1980 s, as compared with that achieved by most other industrial countries (1997).

Lawson's first example of crop yields is a useful illustration of a highly restricted set of differences, but it is likely not representative of many economic subjects of interests. It is a situation where the link between observation and the causal constituents of some phenomena are relatively well understood and where the operation of each possible factor can readily be considered in parts. It is also one in which there is no great controversy regarding the overall framework of theory relevant to the matter under observation (crop yields). It is the closest approximation to laboratory conditions one might find in a social context (and is also for other purposes a subject of laboratory experiment by corporations). One can consider it an economic example in so far as agricultural output is an economic issue and agriculture is part of an economy. But many kinds of issues are far less easily decomposed into their components based on a link between an observable outcome and an identifiable contrast space that seems readily bounded; and few such contrast spaces seem likely to be intrinsically limited in a way most conducive to uncontestable contrast explanations within those bounds. This, of course, is key to Garfinkel's work. Unemployment, inflation, debt levels, income and wealth inequality, well-being etc are not just phenomena of interest that may arise in a contrast space, they are also relational rather than simply events or outcomes as end states of other relations, and highly contested in terms of how they are constituted, and this includes at different scales and based on different conceptions within different broadly based frameworks as theorisations.

Lawson is clearly aware of the problems here. He is by no means making grandiose claims for contrast explanation based on unconvincing examples. Rather he too is attempting to convince that despite the inherent problems of any empirical investigation, contrast explanation remains worthwhile. He specifically differentiates explanation based on well-understood causal mechanisms from attempts to explain what is not well understood (2009). He then also differentiates between pure explanation and applied explanation. Pure explanation of the $\mathrm{x}$ under scrutiny involves positing some previously unknown (perhaps by analogy) mechanism (structures, activity agents etc), creating theory, which is then empirically assessed for adequacy. Applied explanation involves intervention into causal complexes based on cumulative theory.

Inter alia, Lawson's distinction between pure and applied theory is a response to the criticism that, in practice, not all researchers 'start by 'retroducing' from some surprising ['demi-reg'], rather [they are] guided by more abstract and fundamental theoretical propositions' (Arestis, Brown \& Sawyer 2002). Brown in particular argues that there are in fact regularities at the level of system (capitalism) and Marx and other theorists focus on these through abstraction. Though one might dispute the way regularity is redefined in the critique it remains the case that a system as a whole must have emergent properties and these can be expressed in a comprehensive theoretical position. Theory and a grasp of what is emergent can readily combine, since one needs to know how the parts are connected, because those interconnections affect the ways in which the whole is different from the mere sum of its parts. This is essential also for many local explanations. One might then infer that contrast explanation may not be the most appropriate way to investigate all aspects of something that is comprehensively or systemically conceived. 
However, for Lawson, contrast explanation provides one way in which empirical adequacy is explored, and as such fits into a 'dialectic' of knowledge or learning. It is not exclusive and its findings are not definitive. It is in any case an ordinary part of putting the conception of reality to the test (a basic of the genuine practice of fallibility). There is always an 'achieved level' of understanding or knowledge of a domain, which gives rise to expectations for what will occur within that domain. This expectation may then be challenged by observation, and this creates the grounds that provoke contrast explanations, which in turn become part of the process by which any and all understandings (including theory) of the domain may be reformulated or revised. One can thus, in principle, apply contrast explanation in much more complex situations than that indicated by the crop yield example and do so in variously directed ways that also are informed by different positions and theory. The problem remains that complex, macrohistorical, and ethically and political loaded developments are all too easy to interpret from a wide variety of perspectives and theorist can perhaps become overly committed to a single conditioning position. ${ }^{26}$ However, this is not a problem created by contrast explanation it is a collective problem of any knowledge seeking investigation. According to Lawson, one can explore a contrast explanation in a way that limits the complexity that is investigated, whilst not deforming the investigative process. This, of course, is an empirical claim and in the end is either demonstrated or not.

Lawson's second example of contrast explanation sheds some light on this. This is his reconstruction of Akerlof's seminal paper on adverse selection. Akerlof does not use the language of contrast explanation or of causal processes, where some tendency is heavily influenced by a particular factor within the process. However, according to Lawson the focus of the paper is implicitly contrastive, ${ }_{2}$ since Akerlof is concerned with why second hand cars are (surprisingly) significantly cheaper than new ones (rather than similar); it is not about how prices for markets are determined (which would be far broader in terms of its actual focus). The operative process is relatively easily identified because there is ample evidence for the institutions, organizations and sets of relations and logics that affect the outcome (second hand cars are cheaper). The posited explanation is that the buyer has less information regarding the quality of the car than the seller. Sellers know whether they hold a good or a defective car, but buyers do not. Because of the absence of trust, the market price is likely to be somewhere in between the value of a good and defective car. This makes selling a recently new car as second hand less appealing and particularly to those with 'good' new cars, and so the second hand market becomes skewed towards 'lemons', exacerbating problems over time.

Clearly, the core mechanism identified from Akerlof puts aside many potentially significant aspects that may also be causally significant: cars are status goods where the model, age of the car and plate matter to the owner, so depreciation may reflect the

\footnotetext{
${ }^{26}$ Systematic empirical studies about expert judgements show that experts 'neutralize dissonant data and preserve confidence in their prior assessments by resorting to a complex battery of belief- system defenses that, epistemologically defensible or not, make learning from history a slow process and defections from theoretical camps a rarity' (Tetlock 1999, p. 335; see also Tetlock 2005). For instance, many critical political economists relying on Keynesian reasoning, such as Arestis, Brown \& Sawyer (2002), argued before and at the time of the introduction of the euro that the economic impact of the euro and its accompanying institutions is likely to be deflationary and destabilising; that the political impact is profoundly undemocratic; and that the social consequences are likely to be deleterious. Another possible but less relevant and much more ambivalent source of criticism has been the optimal currency area (Robert Mundell, who developed the theory, has been an enthusiastic supporter of the euro; see Patomäki 2013, 60-4). We are not aware of any mainstream economist who would have adopted a (post) Keynesian framework because of the euro crisis. When critical lessons are drawn, they are based on the optimal currency area theory, or on other neoclassical conceptions, or on ad hoc explanations.
} 
degree of status orientation of consumers. The market may also be affected by financing and credit availability within the current state of the economy, or by changes in regulation related to emissions or fuel taxes. The situation may also reflect the lack of institutions to compensate for information asymmetries. However, Lawson does claim that one can draw further inferences from the role of given institutions, relations and practices as general forms with causal implications, applicable elsewhere. This follows analogously though more complexly from the simple contrast explanation argument begun with the crop yield example. The core of Akerlof's argument and the basic mechanism identified by Lawson is a 'low trust information differential'. ${ }^{27}$ Still, one must acknowledge that there is also a difference in the terms of transition or generalisability based on more complex social relational contexts. The car market has an identified causal history, but the generalisability of this is about the nature of a nonspecified set of concepts as a causal process (which cannot have an actual history adverse selection or a low trust information differential as a mechanism in general). A from-as claim is of a different order as generalisable than a crop yield variation readily identified between two places. In any case, Lawson makes no attempt to equate these arguments, so no error of reasoning is committed and the difference does not prevent the inferences regarding causal implications from being insightful or useful.

However, it does follow that claims continue to be contestable, and in this sense contrast explanation is just like any scientific approach. This is clear from Lawson's third example (1997, pp.255-6), one briefly touched upon already, which compares different possible contrast spaces for UK productivity_growth. Lawson notes that in terms of an earlier/later contrast, focussing on one country and particular period of time, Britain's productivity growth was higher during the early post-war period than it had been for most of the preceding century. This suggests possible explanations such as war-time technological developments or post-war boom in world trade. If one sets a different contrast space but focusses on the same X event or outcome, namely the level of UK productivity growth in the period immediately following the war, one generates different why-questions and different possible answers. When Britain's productivity performance until the 1980s is compared to that of other industrial countries, it turns out to have been slower. Lawson attributes at least part of the responsibility for the relatively slow productivity growth in the UK to path-dependent development that led to a more decentralised system of collective bargaining than elsewhere. Britain's history of the craft-based local worker organisation created a situation where resistance against technological changes was relatively strong.

For this explanation Lawson draws on an account of new production processes introduced without negotiation leading to workers resisting technological change. This may well account for the British experience but is contestable in terms of its generalisibility. Unions can be part of a mechanism fostering technological dynamism in various ways. In its heyday, Swedish social democracy included the Rehn-Meidner model as its key component (this is also an interesting case of a deliberately created large-scale social mechanism). The Rehn-Meidner model was based on solidaristic wage policy but also encouraged firms to make technological innovations, by squeezing low-productivity firms and industries. It also helped adjustments to the technological dynamism of the capitalist world economy by means of an active labour-market policy:

27 This begs the question, what is trust and how does it operate in different circumstances (see for example, Morgan and Sheehan, 2015)? 
unemployed were retrained and moved to new employment by the state. ${ }^{28}$ One might infer from this that a contrast explanation does not have generalisable features in the way the Akerlof example seems to indicate. However, all it indicates is that it does not necessarily have this feature unless demonstrated in the particular case, which is no more than to suggest general specification of interesting causal mechanisms need not apply in the same way in different places or at all. This is not a defect of contrast explanation per se, but rather a claim that one should not expect too much (including universality) from any empirical investigation.

However, the point remains that the concept of a contrast space provides a basis for empirical investigation that can then seek to explore many causal factors, with some link to what may or may not turn out to be a main factor; and a mere surprise relative to current understandings may be all that is required to get an explanatory project going. Explanatory claims that result are all potentially corrigible, and these may also be highly partial: 'where the causes bearing on some phenomenon are many, it may well be that any applied explanatory endeavour can, at best, achieve only a highly partial explanation of some concrete phenomenon under some of its aspects.' (Lawson, 2009, p. 410). The implication is then that contrast explanation is modest in its claims to what it can achieve. Lawson argues that it is by synthesising underlying commonalities of significant causal processes that one can make claims for generalisability that then create the basis for new more specific contrast explanation investigations.

\section{Conclusion: what contrast explanation can and cannot contribute to}

Just as in the case of van Fraassen and Garfinkel, Lawson introduces contrast explanation in a particular context for particular purposes. He explicitly introduces it as a consistent addition to ${ }_{2}$ and development from ${ }_{2}$ his work on social ontology. Lawson's use of contrast explanation is given meaning both by its roots in his work on social ontology and the state of economics that provides the grounds for the critique contained in that social ontology. It is not entirely clear that, for Lawson, contrast explanation is the general framework for any and all explanatory causal investigations and it remains the case that there can be many ways to constructively explore an economic issue (see Morgan 2015a; 2016b). Moreover, contrast explanation as set out by Lawson is an approach not a method; at least in terms of the connotations the latter term usually carries. 'Method' typically indicates some tightly, often technically, defined procedure, such as an OLS regression or use of a Lickert scale. As an approach, contrast explanation is nonetheless insightful and useful in terms of exploring the questionanswer logic of causal explanations and highlighting the ontological, epistemological, pragmatic, ethical and political assumptions that scientific questions necessarily involve.

Lawson's particular use of contrast explanation presupposes value in reorienting explanatory endeavour on phenomena with similar causal histories. This seems reasonable. At the same time, it immediately invokes Mill's problem of limitation: how does one restrict the causal history and select from it? This is a basic problem for science of any kind and for empirical investigation in general. Lawson's argument is

\footnotetext{
${ }^{28}$ Another possibility is the 'negotiated involvement' model of relations of production, which involves workers directly intervening in the introduction of a process. This would provide 'functional flexibility' of working practices instead of 'neo-liberal flexibility' of wages and working conditions. For an excellent analysis of the rise and decline of the Swedish model, and discussion on the promises of the 'functional flexibility’ model, see Ryner 2002; for an assessment and further discussion, Patomäki 2003.
} 
ultimately that the well informed social scientist makes these decisions and that social ontology can help provide an underlying understanding of causal processes, and so orient how one looks and what one looks for. Here, one must acknowledge that contrast explanation can only be a further domain of argument for a constructive or structured pluralism (see Dow, 2004; Dobusch and Kapeller, 2012). It can be a domain in which one differentiates between multiple theories or frameworks as plausibly different perspectives on the same phenomenon. For example, a Schumpeterian view of $\mathrm{x}$, a Keynesian view of $\mathrm{x}$, a gendered view of $\mathrm{x}$, an ecological view of $\mathrm{x}$; a focus on agency, a focus on structure etc. Moreover, because it can invoke different points of departure it can be a way to explore different theories of the same phenomenon that make claims about the same explanatory process. For example, how money is created, what causes inequality, etc. These may be in competition or direct contradiction so contrast explanation may bear on these.

In the end contrast explanation offers but one further way in which different theorizations can be engaged in debate, dialogue, and development, and perhaps can be discarded. That is all it can offer, and one must also accept here that ${ }_{2}$ particularly in the social sciences, reality may be significantly under-determined by theory, and several theories may account for the same phenomena of interest. This is not a problem arbitrarily created by philosophy of science or social science but a real issue they have struggled with. Lawson is an optimist here, he places great weight on a dialectic of learning. In the end, of course, economists are either committed to such learning or are not. Psychologists tend to argue we are rather worse at this than we tend to think we are. However, for Lawson, the greatest impediment to progress in economics is not a world that is under-determined by theory (so there can be several possible theories that remain unfalsified); but rather the existence of theory that never quite has to justify its realisticness or relevance in the first place. Instead, it is based on premises and uses methods that are problematic by virtue of what they suggest about the nature of reality.

However the field actually develops in the future, Lawson's contribution to economics has been profound. In a recent paper in Journal of Economic Methodology David Colander (2013) argued that methodologists of economics bear some of the responsibility for the parlous state of the field (and for the global financial crisis in particular). This is because, as a sub-discipline, methodology has become supine, and concerned acritically with what concerns the dominant tendencies in the rest of economics. ${ }^{29}$ This is not something one could ever suggest regarding Lawson's work. If we return to the point from where we began, Lawson's work has helped to reinvigorate methodology and philosophy in economics and to transcend the sub-disciplinary boundaries constructed around them. Contrast explanation is another contribution to this. It offers something methodology in the abstract rarely does, a provisional way forward from the problems also recognized.

\section{References}

Angrist, J. and Pischke, J. 2010. The credibility revolution in economics: How better research design is taking the con out of econometrics. Journal of Economic Perspectives vol. 24 no. 2, 3-30

\footnotetext{
${ }^{29}$ One might also note that even when the criticisms are more pervasive they are ultimately restricted by the basic commitments to 'this is the best we have and this is science rather than non-science' (despite persistent failure. For a good example, see Caballero, 2010.
} 
Arestis, P., Brown, A. and Sawyer, M. 2002. Critical Realism and the political economy of the euro. New York: Levy Economics Institute Working Paper No. 352, http://www.levyinstitute.org/publications/critical-realism-and-the-politicaleconomy-of-the-euro

Association for Heterodox Economics. 2014. Pluralism, Heterodoxy and the Prospects for a New Economics Curriculum: Assessing the Potential of InET, What's the Use of Economics and the CORE Project, http://www.hetecon.net

Botterill, G. 2010. Two kinds of causal explanation. Theoria vol. 76 no. 4, 287-313

Boyer, R. 2013. The present crisis: a trump for a renewed political economy. Review of Political Economy, vol. 25 no. 1, 1-38

Brown, A. 2007. Reorienting critical realism: a system-wide perspective on the capitalist economy. Journal of Economic Methodology vol. 14 no. 4, 499-519

Brown, A. Fleetwood, S. and Roberts, J. 2002. Critical Realism and Marxism London: Routledge

Caballero, R. 2010. After the crisis: Time to deal with the pretense of knowledge syndrome. Journal of Economic Perspectives vol 24 no. 4, 85-102

Chakravartty, A. 2007. A Metaphysics for Scientific Realism: Knowing the Unobservable Cambridge: Cambridge University Press

Colander, D. 2009. The Making of a European Economist. Cheltenham, UK: Edward Elgar.

Colander, D. 2010. Moving beyond the rhetoric of pluralism. Suggestions for an 'inside-the-mainstream' heterodoxy. 36-47 in R. F. Garnett Jr, E. Olsen \& M. Starr (eds.) Economic Pluralism London: Routledge

Colander, D. (2013) The systemic failure of economic methodologists. Journal of Economic Methodology vol 20 no 1, 56-68

Creaven, S. 2000. Marxism and Realism London: Routledge

Dobusch, L. \& Kapeller, J. 2012. Heterodox United versus Mainstream City? Sketching a framework for interested pluralism in economics. Journal of Economic wessues, vol. 46 no. 4, 1035-1057

Dow, S. 2004. Structured pluralism. Journal of Economic Methodology, vol. 11 no. 3, 275-290

Dow, S. 2012. Foundations for New Economic Thinking: A collection of essays. Basingstoke, UK: Palgrave Macmillan

Downward, P. (ed.) 2003. Applied Economics and the Critical Realist Critique. London: Routledge.

Fine, B. 2013. Economics: unfit for purpose. Review of Social Economy, vol. 71 no. 3, 373-389

Fleetwood, S. (ed.) 1999. Critical Realism in Economics: Development and Debate. London: Routledge

Folbre, N. 1994. Who pays for the kids? London: Routledge

Friedman, M. 1982 Review: The Scientific Image. The Journal of Philosophy vol. 79 no. 5, 1982 274-283

Fullbrook, E. (ed.) 2009. Ontology and Economics: Tony Lawson and His Critics. London: Routledge

Garfinkel, A. 1981. Forms of Explanation: Rethinking the Questions in Social Theory. New Haven: Yale University Press

Groff, R. 2004. Critical Realism, Post-Positivism and the Possibility of Knowledge London: Routledge

Grynaviski, E. 2013. Contrasts, counterfactuals and causes. European Journal of international Relations vol. 19 no. 4, 823-46 
Harcourt, G. 2010. The crisis in mainstream economics. Real World Economics Review, issue $53,47-51$

Hitchcock, C. 1996. The role of contrast in causal and explanatory claims. Synthese vol. 107 , no. 3, 395-419

Hitchock, C. 1999. Contrastive explanation and the demons of determinism. British Journal for the Philosophy of Science. Vol. 50, no. 4, 585-612

Hodgson, G. 2009. The Great Crash of 2008 and the reform of economics. Cambridge Journal of Economics, vol. 33 no. 6, 1205-1221

Hollis, M. 1982. Review: Forms of Explanation: Rethinking the Questions in Social Theory. The Journal of Philosophy vol 79 no 5, 283-286

Humphreys, A. 2016. Causation, complexity, and the concert: the pragmatics of causal explanation in international relations. Journal of International Relations and Development, online first DOI: 10.1057/jird.2016.10.

Jackson, P. Runde, J. Dobson P. and Richter, N. 2016. Identifying mechanisms influencing the emergence and success of innovation within national economies: a realist approach. Policy Sciences vol 49 no 3, 233-256

Jo, T. H. Chester, L and D'Ippoliti, C. 2017. (eds) The Routledge Handbook of Heterodox Economics London: Routledge

Lawson, C., Latsis, J. \& Martins, N. (eds.) 2007. Contributions to Social Ontology. London: Routledge

Lawson, T. 1997. Economics \& Reality London: Routledge

Lawson, T. 1999. 'Feminism, Realism and Universalism', Feminist Economics vol $\underline{5}$ no $\underline{2,25-59}$

Lawson, T. 2003. Reorienting Economics London: Routledge

Lawson, T. 2005. The (confused) state of equilibrium analysis in modern economics: an explanation. Journal of Post Keynesian Economics vol. 27 no. $3423-44$

Lawson, T. 2009. Applied economics, contrast explanation and asymmetric explanation. Cambridge Journal of Economics vol. 33 no. 405-419

Lawson, T. 2015a. Essays on the Nature and State of Modern Economics. London: Routledge

Leamer, E. 2010. Tantalus on the road to asymptopia. Journal of Economic Perspectives vol 24 no 2, 31-46

Leamer, E. 1983. Let's take the con out of econometrics. American Economic Review vol. 73 no. $1,31-43$

Lee, F., Pham, X., \& Gu, G. 2013. The UK research assessment exercise and the narrowing of UK economics. Cambridge Journal of Economics, vol. 37 no. 4, 693-717

Lee, F. and Cronin, B. 2016. Handbook of Research Methods and Applications in Heterodox Economics Cheltenham: Edward Elgar

Lewis, P. (ed.) 2004. Transforming Economics. London: Routledge

Lipton, P. 1990. Contrastive explanation. 247-266 in D. Knowles (ed), Explanation and its Limits, Cambridge: Cambridge University Press.

Mackie, J. L., 1965. Causes and Conditions. American Philosophical Quarterly, vol. 2 no. 4, 245-265

Mackie, J. L., 1980. The Cement of the Universe: A Study of Causation Oxford: Oxford University Press

Morgan J. 2013. Forward-looking contrast explanation, illustrated using the Great Moderation. Cambridge Journal of Economics vol. 37 no. 4, 737-758

Morgan J. 2015a. Piketty's calibration economics: inequality and the dissolution of solutions? Globalizations vol. 12 no. 5, 803-823 
Morgan. J. 2015b. Is economics responding to critique? What do the UK QAA 2015 Subject Benchmarks for Economics indicate? Review of Political Economy, vol. 27 no. $4,518-538$

Morgan, J. 2016a. The Contemporary Relevance of a Cambridge tradition: Economics as political economy, political economy as social theory and ethical theory. Cambridge Journal of Economics, vol. 40 no. 2, 663-700

Morgan, J. 2016b. Corporation tax as a problem of MNC organisational circuits: The case for unitary taxation. British Journal of Politics and international Relations vol. 18 no. $2,463-481$

Morgan, J. and Sheehan, B. 2015. The concept of trust and the Political Economy of John Maynard Keynes, illustrated using central bank Forward Guidance and the democratic dilemma in Europe. Review of Social Economy, vol. 73 no. 1, 113137

Norris, C. 2002. Hilary Putnam: Realism, Reason and the Uses of Philosophy Manchester: Manchester University Press

Northcott, R. 2008. Causation and contrast classes. Philosophical Studies vol 139 no. 1, 111-123

O’Boyle, B. and McDonough, T. 2011. Critical Realism, Marxism and the Critique of Neoclassical Economics. Capital \& Class vol. 34 no. 1, 3-22

Patomäki, H. 2003. Explaining the rise and fall of the Swedish model. Cooperation \& Conflict vol. 38 no. 2, 175-178

Patomäki, H. 2010. After Critical Realism? The relevance of contemporary science. Journal of Critical Realism, vol. 9, no. 1, 59-89

Patomäki, H. 2013. The Great Eurozone Disaster: From Crisis to Global New Deal. London: Zed Books

Patomäki, H. 2014. On the reality of causes: a response to Ned Lebow. Newsletter of Qualitative and Multi-Method Research, American Political Science Association, vol. 12 no. 2, 11-15; available at http://www.maxwell.syr.edu/ uploadedFiles/moynihan/cqrm/Newsletter\%2012_2.pdf.

Patomäki, H. 2016. Praxis, politics and the future: a dialectical critical realist account of world-historical causation. Journal of International Relations and Development, online first doi:10.1057/jird.2016.17

Pratten, S. (ed.) 2015. Social Ontology and Modern Economics. London: Routledge

Ryner, M. 2002. Capitalist Restructuring, Globalisation and the Third Way. Lessons from the Swedish Model. London: Routledge

Rodrik, D. 2015. Economics Rules: The Rights and Wrongs of the Dismal Science London: Norton

Sawyer, M. 2011. 'It' keeps happening: Post Keynesian views on the financial crisis and the great recession. History of Economic Ideas, vol. 19 no. 2, 149-164

Spash, C. 2013. The shallow or the deep ecological economics movement? Ecological Economics, 93, 351-362

Syll, L. 2016. When the model becomes the message - a critique of Rodrik. Real World Economics Review issue 74, 139-155

Tetlock, P. 1999. Theory-driven reasoning about plausible pasts and probable futures in world politics: are we prisoners of our preconceptions? American Journal of Political Science vol. 43 no. 2, 335-66

Tetlock, P. 2005. Expert Political Judgement. How Good Is It? How Can We Know?. Princeton NJ: Princeton University Press.

Turner, S. 1984. Review: Forms of Explanation: Rethinking the Questions in Social Theory. Philosophy of the Social Sciences vol 14 no 3, 416-418 
Van Fraassen, B. 1980. The Scientific Image Oxford: Clarendon

Van Fraassen, B. 2008. Scientific Representation: paradoxes of perspective Oxford: Clarendon

Webb, J. 1983. Review: Forms of Explanation: Rethinking the Questions in Social Theory. Journal of Economic Issues vol 17 no 3, 813-817 